\title{
Increasing serotonin concentrations alter calcium and energy metabolism in dairy cows
}

\author{
Jimena Laporta ${ }^{1,}$, Spencer A E Moore ${ }^{1}$, Samantha R Weaver ${ }^{1}$, Callyssa M Cronick ${ }^{1}$, \\ Megan Olsen', Austin P Prichard', Brian P Schnell', Thomas D Crenshaw', \\ Francisco Peñagaricano ${ }^{2,+}$, Rupert M Bruckmaier ${ }^{3}$ and Laura L Hernandez ${ }^{1}$ \\ Departments of ${ }^{1}$ Dairy Science, and ${ }^{2}$ Animal Sciences, University of Wisconsin-Madison, 1675 Observatory Drive, \\ Madison, Wisconsin 53706, USA \\ ${ }^{3}$ Veterinary Physiology, Vetsuisse Faculty, University of Bern, $\mathrm{CH}-3001$ Bern, Switzerland \\ 'J Laporta and F Peñagaricano are now at Department of Animal Sciences, University of Florida, \\ Gainesville, Florida 32611, USA
}

Correspondence should be addressed to L L Hernandez

Email

Ilhernandez@wisc.edu

\begin{abstract}
A $4 \times 4$ Latin square design in which varied doses $(0,0.5,1.0$, and $1.5 \mathrm{mg} / \mathrm{kg})$ of 5-hydroxy-L-tryptophan (5-HTP, a serotonin precursor) were intravenously infused into late-lactation, non-pregnant Holstein dairy cows was used to determine the effects of serotonin on calcium and energy metabolism. Infusion periods lasted 4 days, with a 5-day washout between periods. Cows were infused at a constant rate for $1 \mathrm{~h}$ each day. Blood was collected pre- and 5, 10, 30, 60, 90, and 120 min post-infusion, urine was collected pre- and post-infusion, and milk was collected daily. All of the 5-HTP doses increased systemic serotonin as compared to the $0 \mathrm{mg} / \mathrm{kg}$ dose, and the 1.0 and $1.5 \mathrm{mg} / \mathrm{kg}$ doses increased circulating glucose and non-esterified fatty acids (NEFA) and decreased beta-hydroxybutyrate ( $\beta$ HBA) concentrations. Treatment of cows with either 1.0 or $1.5 \mathrm{mg} / \mathrm{kg} 5$-HTP doses decreased urine calcium elimination, and the $1.5 \mathrm{mg} / \mathrm{kg}$ dose increased milk calcium concentrations. No differences were detected in the heart rates, respiration rates, or body temperatures of the cows; however, manure scores and defecation frequency were affected. Indeed, cows that received 5-HTP defecated more, and the consistency of their manure was softer. Treatment of late-lactation dairy cows with 5-HTP improved energy metabolism, decreased loss of calcium into urine, and increased calcium secretion into milk. Further research should target the effects of increasing serotonin during the transition period to determine any benefits for post-parturient calcium and glucose metabolism.
\end{abstract}

$\begin{aligned} & \text { Key Words } \\ & \text { - serotonin } \\ & \text { - NEFA } \\ & \text { - insulin } \\ & \text { - glucose } \\ & \text { - BHBA } \\ & \text { - calcium } \\ & \text { - PTHrP }\end{aligned}$

\section{Introduction}

Serotonin is an evolutionary conserved monoamine that is biochemically derived from the essential amino acid L-tryptophan. Tryptophan hydroxylase (TPH) converts L-tryptophan into 5-hydroxy-L-tryptophan (5-HTP), which is then converted into serotonin by aromatic amino acid decarboxylase. The expression of two independent enzymes, TPH1 and TPH2 (Cote et al. 2003), results in two independent serotonergic systems: a neuronal system (CNS, wherein TPH2 is the rate-limiting enzyme) and a non-neuronal system (peripheral, wherein 
TPH1 is the rate-limiting enzyme). Serotonin controls a wide range of biological functions. Serotonin's role as a neurotransmitter in the CNS and its participation in a variety of behavioral functions has been largely documented (Lucki 1998). However, the significance of nonneuronal serotonin is not thoroughly appreciated, despite numerous studies having been conducted on serotonin in a variety of tissues and physiological states (Berger et al. 2009, Amireault et al. 2013). Only a small percentage ( $\sim 5 \%$ ) of the body's total serotonin is found in the CNS, with the majority ( $\sim 95 \%$ ) being stored in the platelets and being derived from variety of tissues outside of the CNS (Berger et al. 2009).

Serotonin is synthesized by the mammary gland in several species (Matsuda et al. 2004, Hernandez et al. 2009), and it regulates several aspects of mammary gland function, including milk protein gene expression, the induction of parathyroid hormone-related protein (PTHrP) production, and mammary gland Ca pumps and transport (Matsuda et al. 2004, Hernandez et al. 2012, Laporta et al. 2013a, 2014a). The concept that the mammary gland acts as an endocrine organ that secretes PTHrP into the circulation as a signal to target tissues to regulate Ca supply to the milk during lactation is well accepted in rodents and humans (Wysolmerski 2010). However, these regulatory pathways have not been thoroughly explored in dairy cows. Serotonin is directly involved in bone metabolism via the decreasing of bone formation and the stimulation of bone resorption (Ducy 2011). In fact, serotonin-deficient male mice exhibit reduced bone resorption (Chabbi-Achengli et al. 2012). Therefore, it is possible that serotonin impacts bone directly and indirectly by stimulating PTHrP synthesis by the mammary gland during lactation to induce bone resorption (Horseman \& Hernandez 2014).

Several lines of evidence suggest a role for serotonin in the regulation of energy balance (Tecott 2007), mainly through the modulation of glucose and lipid metabolism. The liver expresses TPH1 and several serotonin receptor subtypes (Papadimas et al. 2012). Serotonin is thought to mediate hepatic regeneration (Lesurtel et al. 2006) as well as glucose and insulin secretion (Sugimoto et al. 1990). Studies have shown that serotonin is involved in liver glucose uptake mechanisms (Moore et al. 2005) and glycogen metabolism (Papadimas etal. 2012). Additionally, serotonin has been shown to be increased in mice that are subjected to fasting conditions, which results in the stimulation of lipolysis and liver gluconeogenesis via the serotonin receptor $2 \mathrm{~b}$ subtype in adipocytes and hepatocytes (Sumara et al. 2012). Furthermore, mice that were injected with increasing doses of serotonin responded by proportionally increasing free fatty acids (Sumara et al. 2012).

The role of serotonin during lactation has been primarily explored in rodents, and there is limited information in dairy cows. We hypothesized that increasing systemic serotonin concentrations in lactating dairy cows would improve $\mathrm{Ca}$ and energy metabolism. In the present study, we therefore performed a 5-HTP dosing experiment to explore the effects of increasing serotonin on $\mathrm{Ca}$ and energy metabolism in late-lactation Holstein cows.

\section{Materials and methods}

\section{Animals and experimental design}

All of the experiments were performed under protocols approved by the Animal Care and Use Committee at the University of Wisconsin-Madison. Four $(n=4)$ non-pregnant late-lactation (333 \pm 7 days in milk; average lactation parity 3; average milk yield $21 \pm 2.7 \mathrm{~kg}$ ) Holstein dairy cows were utilized for the present experiment. Cows were enrolled in the experiment 2 weeks before the initiation of sample collection to allow for acclimation and were housed in a tie-stall barn. Cows were fed a standard lactating cow diet and given a mill grain mix (MK1283B, VitaPlus, Lake Mills, WI, USA).

The experimental design was a $4 \times 4$ Latin square. Four 5-HTP doses were used in the infusions: $0 \mathrm{mg} / \mathrm{kg}$ (saline, CON), $0.5 \mathrm{mg} / \mathrm{kg}$ (0.5 dose), $1 \mathrm{mg} / \mathrm{kg}$ (1.0 dose), and $1.5 \mathrm{mg} / \mathrm{kg}$ (1.5 dose) per body weight of the cows. Doses were i.v. infused with jugular catheters at a constant rate for $1 \mathrm{~h}$ for 4 days. The experiment included a 2-week acclimation period, a 5-day baseline period before the initiation of treatments, and four treatment periods (of 4 days each), with a 5-day washout period between treatment periods. The experimental design and timeline are summarized in Fig. 1. During the baseline period, blood, urine, and milk samples were collected, and milk production was recorded daily for 5 days. During each infusion period (I-IV), milk samples were collected and milk production was recorded daily, urine was collected pre- and post-infusion, and blood samples were collected pre-infusion (at $0 \mathrm{~min}$ ) and post-infusion (at 5, 10, 30, 60, 90, and $120 \mathrm{~min}$ ). Heart rate (HR), respiration rate (RR), and rectal temperature (RT) were recorded once preinfusion, every $15 \mathrm{~min}$ during infusion, and $15 \mathrm{~min}$ post-infusion to monitor cow health. Manure (defecation) frequency (MF) and manure score (MS, $0=$ normal to $4=$ diarrhea) were recorded during infusion. Liver tissue biopsies were collected at the beginning of the experiment

Published by Bioscientifica Ltd. 


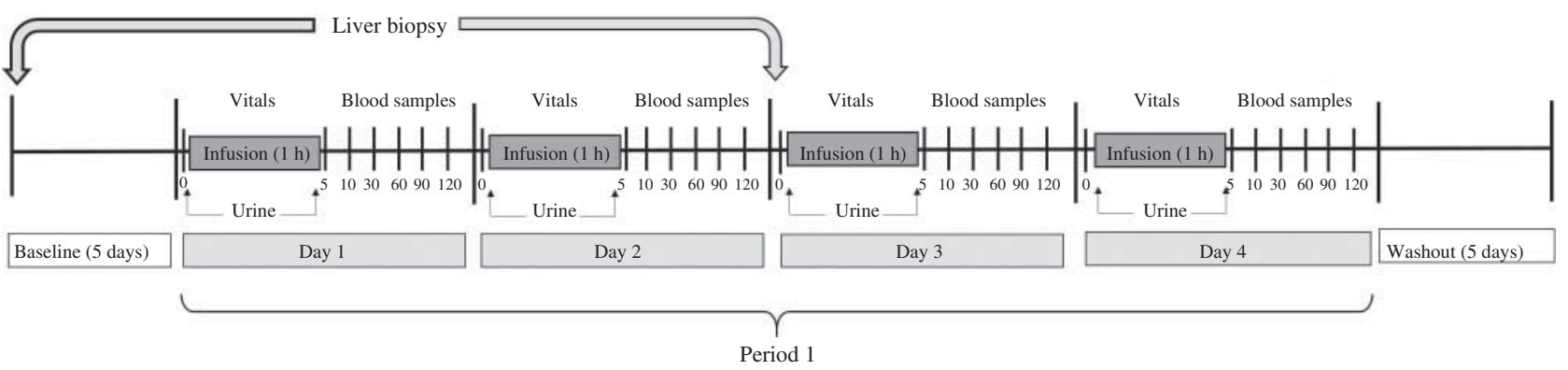

Figure 1

Schematic representation of the experimental design. Four doses $(0,0.5$, 1.0 , and $1.5 \mathrm{mg} / \mathrm{kg}$ ) of 5-hydroxy-L-tryptophan (5-HTP) were infused intravenously (at a constant rate for $1 \mathrm{~h}$ ) for 4 days (1-4) into four Holstein dairy cows in a $4 \times 4$ Latin square design. There were a total of four infusion periods (with a 5-day washout period in between each infusion period). Only period I is shown here as an example. Before the initiation of period I, blood, urine, and milk samples were collected daily for 5 days (baseline). Milk samples were collected daily (morning milking), urine samples were

for all of the cows (baseline) and on day 2 (after completion of the infusion) in each period. Blood, urine, and milk samples were collected daily in the morning and during the washout periods to monitor possible carryover effects of the applied doses between periods.

\section{Sample collection}

Before the initiation of each period, catheters (Abbocath- $T$ Subclavian i.v. $14 \mathrm{~g} \times 5$ 1/2' Catheter, Hospira, Lake Forest, IL, USA) were inserted into the jugular vein and sutured to skin that had been previously clipped and scrubbed. Catheters were flushed with sterile saline containing $10 \mathrm{IU}$ of heparin every $8 \mathrm{~h}$. Whole blood samples were collected from the jugular catheter during infusion periods or from the coccygeal vein during washout periods. To harvest the serum and plasma fractions, $10 \mathrm{ml}$ BD Vaccutainer Serum Plus (367820, BD, Franklin Lakes, NJ, USA) and Lithium Heparin 158 USP Units Plus Blood Collection Tubes (367880, BD) were used respectively. Samples were centrifuged at $3000 \boldsymbol{g}$ for $20 \mathrm{~min}$ at $4{ }^{\circ} \mathrm{C}$, and the serum and plasma fractions were collected and stored at $-80^{\circ} \mathrm{C}$ until analysis.

Urine samples were obtained by gentle massage of the area between the udder attachment and the lower portion of the vulva. Mid-stream urine samples were collected in sterile propylene tubes that were stored at $-20^{\circ} \mathrm{C}$ until analysis. Milk samples were collected during the morning milking in a sterile tube and kept at $-20^{\circ} \mathrm{C}$ until analysis. Percutaneous liver biopsy samples were collected. Cows were given an i.v. sedative and analgesic cocktail $(0.02 \mathrm{mg} / \mathrm{kg}$ butorphanol, Fort Dodge Laboratories (Fort Dodge, IA, USA), and $0.02 \mathrm{mg} / \mathrm{kg}$ xylazine, AnaSed (Shenandoah, IA, USA)), and collected pre- and post-infusion, and blood samples were collected pre-infusion (at $0 \mathrm{~min}$ ) and post-infusion (at 5, 10, 30, 60, 90, and $120 \mathrm{~min}$ ). Animal health parameters (heart rate, respiration rate, and rectal temperature) were recorded pre-infusion, every 15 min during infusion, and 15 min post-infusion. Manure frequency and score were recorded during infusion. Liver tissue was harvested at the beginning of the baseline period and on day 2 during each of the four infusion periods. Blood, urine, and milk samples were collected daily during the washout periods as well.

the surgical site was then prepared with betadine surgical scrub (Veterinary, Purdue Products, Stamford, CT, USA) and $70 \%$ ethanol. Local anesthetic (10 $\mathrm{ml}$ of $5 \%$ lidocaine, Sparhawk Laboratories, Mission, KS, USA) was administered at the biopsy site. Liver tissue was snap-frozen in liquid nitrogen and stored at $-80^{\circ} \mathrm{C}$ until analysis.

\section{Serum and plasma laboratory analysis}

For all of the assays performed in the laboratory, samples were randomized and a quality control (QC) was analyzed on each plate. Blood serum serotonin was measured with a Serotonin Enzyme Immunoassay (EIA) Kit, (IM1749, Immunotech, Beckman Coulter, Marseille Cedex 9, France). Samples were diluted 1:100 in order to fall within the range of the standard curve of the assay. The intra- and inter-assay coefficient of variations $(\mathrm{CV})$ were 2.3 and $7.3 \%$ respectively. Serum and urine total Ca concentrations were measured with a colorimetric Ca assay kit (no. 700550, Cayman Chemical Company, Ann Arbor, MI, USA) according to the manufacturer's instructions; the intraassay $\mathrm{CV}$ was $<9.7 \%$, and the inter-assay $\mathrm{CV}$ was $<13 \%$ for both assays. Total milk Ca was measured by atomic absorption spectrophotometry (Perkin-Elmer Model 2280, Perkin-Elmer Corp., Norwalk, CT, USA) procedures as described previously (Rortvedt \& Crenshaw 2012, Laporta et al. 2014a) with the addition of a hydrochloric acid digestion step. The intra-assay CV was $<2.3 \%$.

Plasma glucose concentrations were measured with a glucose oxidase-peroxidase assay specific for glucose (Karkalas 1985). The intra- and inter-assay CV were 6.7 and $7.5 \%$ respectively. Plasma insulin was measured in

Published by Bioscientifica Ltd 
duplicate by RIA as described previously (Vicari et al. 2008), and the intra- and inter-assay CV were both $<4 \%$. Serum non-esterified fatty acid (NEFA) concentrations were measured with an enzymatic colorimetric assay (NEFA-HR (2), Wako Chemicals, Richmond, VA, USA). The intra- and inter-assay CV were 3.9 and $6.4 \%$ respectively. Plasma concentrations of beta-hydroxybutyrate $(\beta \mathrm{HBA})$ were measured enzymatically with kit no. RB1007 from Randox Laboratories Ltd (Ibach, Switzerland). The intra- and inter-assay CV were 2.8 and $4 \%$ respectively. Plasma PTHrP was measured with a PTHrP Immunoradiometric Assay Kit (DSL8100, Immunotech, Beckman Coulter, Prague, Czech Republic) per the manufacturer's instructions, and the inter-assay CV was $15 \%$.

\section{Hepatic gene expression}

Total RNA was isolated from liver tissue using TRI-Reagent (Molecular Research Center, Cincinnati, OH, USA) according to the manufacturer's instructions. Total RNA concentration and absorbance ratios were quantified by a Nanodrop spectrophotometer (ND-1000, Nanodrop Technologies, Wilimington, DE, USA). One microgram of total RNA was reversed transcribed with iScript Reverse Transcription Supermix for RT-qPCR Kit (no. 1708841, BioRad, Hercules, CA, USA) and diluted (1:5) in deionized water. Quantitative PCR was conducted with the CFX96 Touch Real-Time PCR Detection System (BioRad) using SSoFast EvaGreen Supermix (no. 1725203, BioRad) as described previously (Laporta et al. 2013a). We evaluated the hepatic expression of genes associated with glucose, fatty acid, and ketone metabolism, including: 3-hydroxy-3-methylglutaryl-CoA synthase
(HMG-COA), pyruvate carboxylase (PC), pyruvate dehydrogenase kinase, isozyme 4 (PDK4), glucose-6-phosphatase $(G 6 P)$, carnitine palmitoyltransferase 1 (CPT1), acyl-CoA dehydrogenase, very long chain $(A C A D V L)$, peroxisome proliferator-activated receptor $\alpha(P P A R \alpha)$, and acyl-CoA oxidase 1, palmitoyl (ACOX1). The average of $\beta$-actin, ribosomal protein 9 (RSP9), and ribosomal protein 15 (RSP15) were used as the housekeeping (internal control) gene. Data were analyzed using the $2^{-\Delta \Delta C t}$ method, with the baseline day serving as the control (Livak \& Schmittgen 2001). The primer sequences used are presented in Table 1.

\section{Protein isolation and analysis}

Protein was isolated from the liver tissue using radioimmunoprecipitation assay buffer (RIPA) plus $10 \mu \mathrm{l} / \mathrm{ml}$ of Halt Protease and Phosphatase Inhibitors Cocktail (no. 78441, Thermo Scientific, Grand Island, NY, USA). Protein concentrations were determined by a Bicinchoninic Acid Assay (no. 23227, Pierce Chemicals, Grand Island, NY, USA). Liver serotonin concentrations were determined with a Serotonin EIA Kit (IM1749, Immunotech, Beckman Coulter) using $50 \mu \mathrm{g}$ protein per sample analyzed as reported previously (Matsuda et al. 2004, Laporta et al. 2013b, 2014a).

\section{Statistical analysis}

The experimental design was a $4 \times 4$ Latin square. The final model that was used to analyze the variables with $\mathrm{R}$ Software (R Development Core Team 2014) was:

$\mathrm{y}=\mu+C+R+\mathrm{TR}+D+T+\mathrm{TR} \times D+\mathrm{TR} \times T+$ error

Table 1 Primer sequences for the studied genes quantified by real-time PCR. All of the primers were designed using Primer 3 (Rozen \& Skaletsky 2000) and were run at an annealing temperature of $60^{\circ} \mathrm{C}$. The average of $\beta$-actin, ribosomal protein 9 (RSP9), and ribosomal protein 15 (RSP15) were used as the housekeeping (internal control) gene.

\begin{tabular}{l} 
Genes \\
\hline$A C A D V L$ \\
ACOX \\
$C P T 1$ \\
G6P \\
HMG-COA \\
$P C$ \\
PDK4 \\
PPAR $\alpha$ \\
$\beta-A C T I N$ \\
$R S P 9$ \\
$R S P 15$
\end{tabular}

\begin{tabular}{l} 
Forward primer $\mathbf{5}^{\prime} \mathbf{- 3}^{\prime}$ \\
\hline CCAGCCCCTGTGGAAAATACTA \\
CCATTGCCGTCCGATACAGT \\
GAGACAGACACCATCCAGCA \\
TGATGGACCAAGAAAGATCCAGGG \\
TCTGGCCCATCACTCTGCC \\
CCACGAGTTCTCCAACACCT \\
AAAGCCCAGAGGACCAAAAG \\
CGGTGTCCACGCATGTGA \\
CACCTTCACCGTTCCAGTTT \\
GGAGACCCTTCGAGAAGTCC \\
CGCGACATGATCATTCTACC
\end{tabular}

\begin{tabular}{l} 
Reverse primer $\mathbf{5}^{\prime} \mathbf{- 3}^{\prime}$ \\
\hline GCCCCCGTTACTGATCCAA \\
GTTTATATTGCTGGGTTTGATAATCCA \\
TCGTGGTAGAGCCAGACCTT \\
TAGGGATTGACCTCACTGGCCCTCTT \\
AGTGGGGAGCCTGGAGAAGC \\
TTCTCCTCCAGCTCCTCGTA \\
GCATCCGGGTAGAAATACGA \\
TCAGCCGAATCGTTCTCCTAAA \\
ACTTGCGCAGAAAACGAGAT \\
CTTTCTCATCCAGCGTCAGC \\
TTACTTGAGGGGGATGAAGC
\end{tabular}

$A C A D V L$, acyl-COA dehydrogenase; very long chain, ACOX1, acyl-CoA oxidase $1 ;$; $C P T 1$, carnitine palmitoyltransferase $1 ;$ G6P, glucose-6-phosphatase; $H M G$ $C O A$, 3-hydroxy-3-methylglutaryl-CoA synthase; $P C$, pyruvate carboxylase; PDK4, pyruvate dehydrogenase kinase, isozyme 4; $P P A R \alpha$, peroxisome proliferator-activated receptor $\alpha$. 
where $\mu$ was the mean, $C$ was the effect of the column (period 1-4), $R$ was the effect of the row (cow), TR was the effect of the dose (categorical), $D$ was the effect of the day of infusion (1-4, categorical), and $T$ was the effect of time (0-120 min, categorical). All of the effects were considered fixed. For circulating $\mathrm{Ca}$, PTHrP, glucose, NEFA, $\beta \mathrm{HBA}$, and insulin, the area under the curve (AUC, according to the trapezoidal method) was calculated by the same model without the time (0-120 min) effect. Normality and outlier tests were performed for all of the variables analyzed. Transformations of serotonin (square root transformation) and $\mathrm{Ca}$ (natural log transformation) variables were required because of the lack of normality of the data. For all of the analyses, differences between means were considered significant at $P<0.05$. All values are reported as LS means \pm s.E.M.

\section{Results}

\section{Animal health and milk production are not affected by 5 -HTP infusion}

Cow vital signs were evaluated as a measurement of cow health status during 5-HTP infusions. All of the vital signs analyzed, including $\mathrm{HR}, \mathrm{RR}$, and rectal RT, were not different among the cows that received any dose of 5-HTP as compared to the CON ( $P>0.05$; Fig. $2 \mathrm{~A}, \mathrm{~B}$, and $\mathrm{C})$.
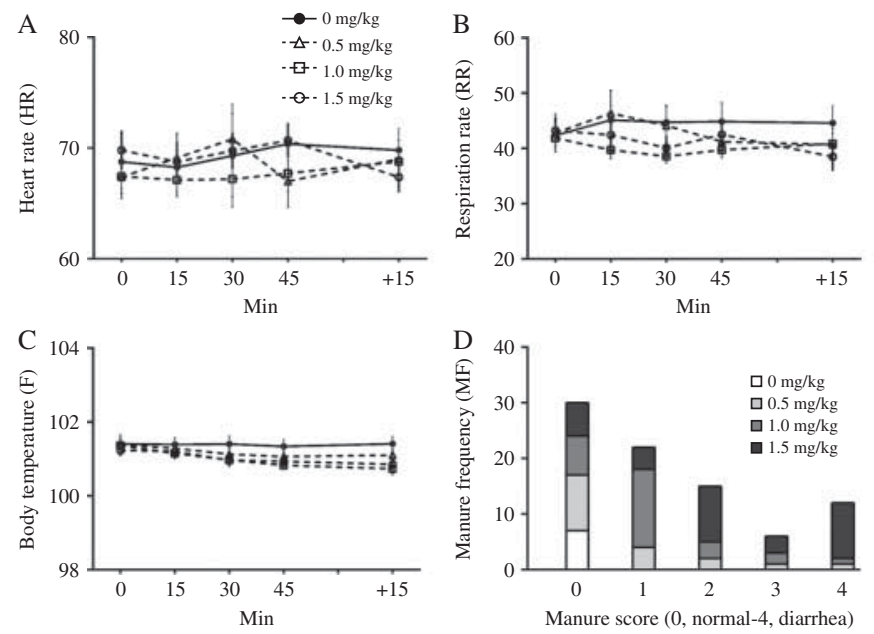

Figure 2

Animal health parameters and serum serotonin concentrations in response to 5-HTP infusion. (A) Heart rate (beats/min), (B) respiration rate (inhalations $/ \mathrm{min}$ ), (C) rectal temperature $\left({ }^{\circ} \mathrm{Fahrenheit},{ }^{\circ} \mathrm{F}\right),(\mathrm{D})$ manure score $(0=$ normal to $4=$ diarrhea) were monitored pre- (0), every $15 \mathrm{~min}$ $(15,30$, and 45$)$ during $1 \mathrm{~h}$ of continuous i.v. infusion of four doses of 5-HTP $(0,0.5,1.0$, or $1.5 \mathrm{mg} / \mathrm{kg})$, and $15 \mathrm{~min}$ post-infusion (+15) into late-lactation,
Additionally, milk production was measured to ensure that 5-HTP infusion had no negative effects on milk yield. Milk production was not different between cows that received any dose of 5 -HTP as compared to the CON $(P=0.15$; data not shown). Manure score was increased with increased 5-HTP dose $(P=0.01)$. The MS was increased for the 1.0 and 1.5 doses as compared to the CON $(0.44$ for CON vs 1.69 and $2.06 \pm .33$ for the 1.0 and 1.5 doses respectively). For the CON cows, the MF was always 0 , and only cows that were infused with 5-HTP (at all doses) had an MF $>0$ (1-4); the MF increased in a dosedependent manner (Fig. 2D). Defecation frequency was increased with increased 5-HTP dose, and it was also increased with more days of treatment $(P<0.04)$. All of the cows that received 5-HTP doses defecated more frequently than the CON (Fig. 2D). Defecation frequency peaked on day 3 of 5-HTP infusion.

\section{Circulating serotonin concentrations are increased by 5-HTP infusion}

Serotonin AUC tended to be affected by 5-HTP dose $(P=0.07)$. The AUC was increased in response to the 1.5 dose as compared to the CON ( $P=0.06$; data not shown). Serotonin concentrations were affected by 5 -HTP dose and days of infusion $(P<0.0002$; Fig. $2 \mathrm{E}$ and $\mathrm{F})$. Serotonin was elevated by all of the 5 -HTP doses as compared to the CON
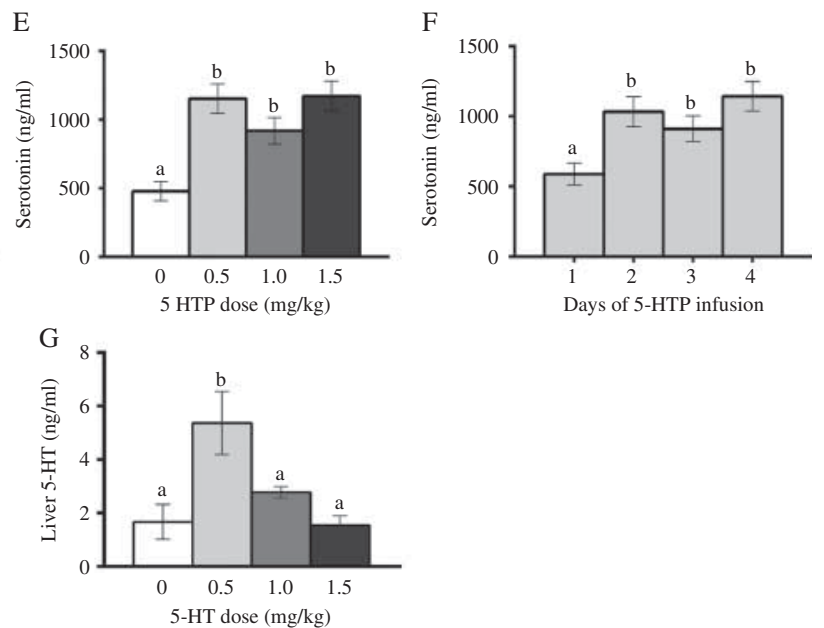

non-pregnant Holstein dairy cows $(n=4)$. Defecation frequency was monitored only during 5-HTP infusion (D). ( $E$ and F) Circulating serotonin concentrations in response to (E) treatment (5-HTP dose) (E) and day of infusion (1-4) (F). (G) Hepatic concentrations of serotonin by 5-HTP dose. Different letters indicate statistical differences between group means (Tukey's $P<0.05$ ). Data are presented as LS means \pm s.E.M. 
$(P<0.002)$, and all of the doses of 5-HTP resulted in similar circulating serotonin concentrations $(P>0.05$; Fig. $2 \mathrm{E})$. Serotonin concentrations were increased on days 2,3 , and 4 as compared to day 1 of infusion $(P<0.04$; Fig. $2 \mathrm{~F})$. Hepatic serotonin content was increased by the 0.5 dose $(P=0.01)$ and tended to be elevated in response to the 1.0 dose $(P=0.09)$ as compared to the CON (Fig. 2G). No statistical differences between baseline serotonin concentrations and the washout periods were observed $(P>0.05)$.

\section{Circulating glucose concentrations are increased by 5-HTP infusion}

Glucose AUC was affected by 5 -HTP dose $(P=0.02)$. The AUC was increased for the 1.0 dose as compared to the 0.5 dose (data not shown). Glucose concentrations were also affected by 5 -HTP dose $(P<0.0001$; Fig. $3 \mathrm{~A})$ and tended to be increased with time after infusion $(P=0.10)$. Overall glucose concentrations were increased by the 1.0 dose
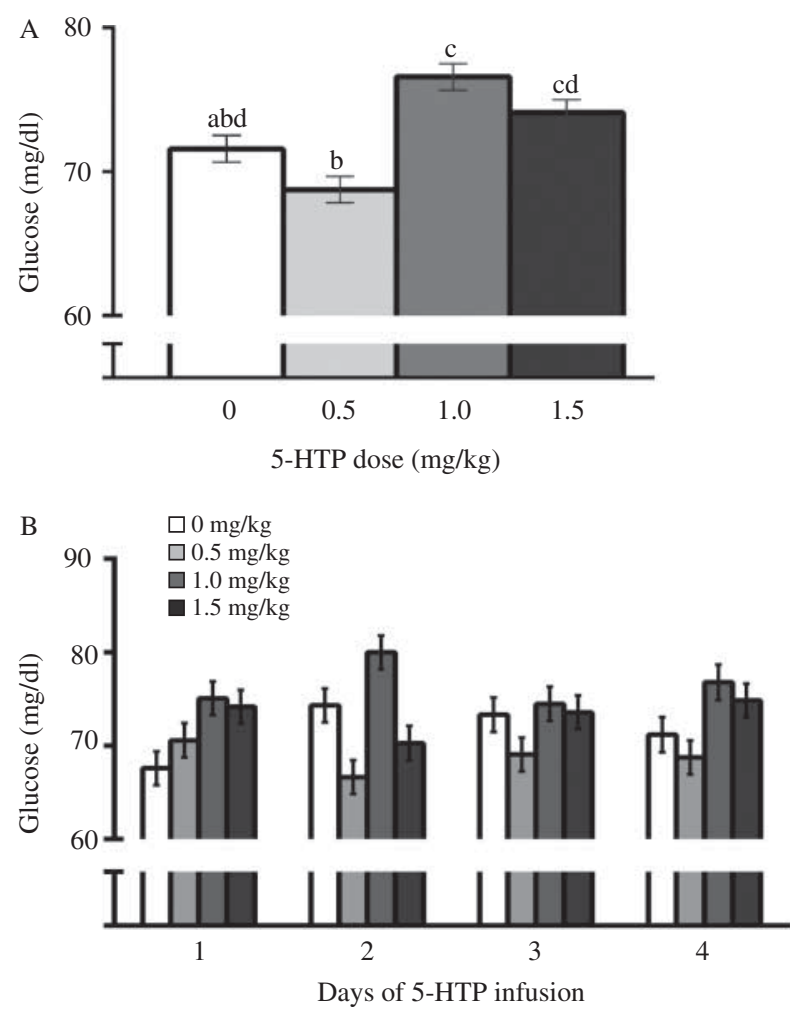

Figure 3

Circulating glucose levels in response to the i.v. infusion of four 5-hydroxyL-tryptophan (5-HTP) doses $(0,0.5,1.0$, and $1.5 \mathrm{mg} / \mathrm{kg})$ for 4 consecutive days into late-lactation, non-pregnant Holstein dairy cows $(n=4)$. (A) Main effect of treatment (5-HTP dose). (B) Interaction between day of infusion and 5-HTP dose. Different letters indicates statistical differences between group means (Tukey's $P<0.05$ ). Data are presented as means \pm s.E.M. as compared to the 0.5 dose and the CON $(P<0.001)$ and by the 1.5 dose as compared to the 0.5 dose $(P=0.002$; Fig. 3A). Glucose concentrations tended to be increased at $120 \mathrm{~min}$ as compared to $30 \mathrm{~min}$ after infusion $(P=0.07)$. Glucose concentrations were increased in the 1.0 dose as compared to the CON at 90 min post-infusion $(P=0.05)$, and the 1.0 and 1.5 doses tended to be increased as compared to the CON at 120 min post-infusion $(P<0.09)$. Glucose concentrations were not different across the 4 days of infusion, but there was a significant dose by day interaction $(P=0.006)$. Briefly, on day 1 , glucose levels increased with the highest doses of 5-HTP as compared to the CON; however, this pattern was maintained only for the 1.0 dose on days 2 and 4 (Fig. 3B). No statistical differences between the baseline glucose concentrations and the washout periods were observed ( $F$-test, $P>0.05$ ).

\section{Circulating insulin concentrations are decreased by 5-HTP infusion}

The AUC for plasma insulin was decreased in response to all of the 5-HTP doses as compared to the CON $(P<0.005)$. Circulating insulin concentrations were affected by 5 -HTP dose, by time after infusion $(P<0.0001$; Fig. $4 \mathrm{~A}$ and $\mathrm{B})$, and by dose-by-time and dose-by-day interactions $(P<0.0005$; Fig. 4C and D). All of the 5-HTP doses decreased insulin concentrations as compared to the CON $(P<0.0001$; Fig. 4A). Insulin concentrations decreased markedly after the first 5 min post-infusion for all of the 5-HTP doses as compared to the CON (Fig. 4B) and remained lower than the CON but began to increase at 90 and 120 min postinfusion as compared to 5,10 , and 30 min post-infusion. The decrease in insulin concentration was less dramatic for the 0.5 dose as compared to the other 5-HTP doses, particularly on days 2 and 4 (Fig. 4C). No statistical differences between the baseline insulin concentrations and the washout periods were observed $(P>0.05)$.

\section{Circulating NEFA concentrations are increased by 5-HTP infusion}

The AUC for NEFA was increased in response to all of the doses of 5-HTP treatment $(P=0.0004)$. The AUC for NEFA was greatest for the 1.0 and 1.5 doses as compared to the CON $(P<0.001$; data not shown). Circulating NEFA concentrations were affected by 5 -HTP dose, by time after infusion, and by day of infusion $(P<0.004$; Fig. $5 \mathrm{~A}, \mathrm{~B}$, and C). There were significant dose-by-day ( $P=0.000$; Fig. 5D) and dose-by-time interactions ( $P=0.01$; Fig. $5 \mathrm{E})$. Overall, all 5-HTP treatments increased NEFA concentrations as

Published by Bioscientifica Ltd 

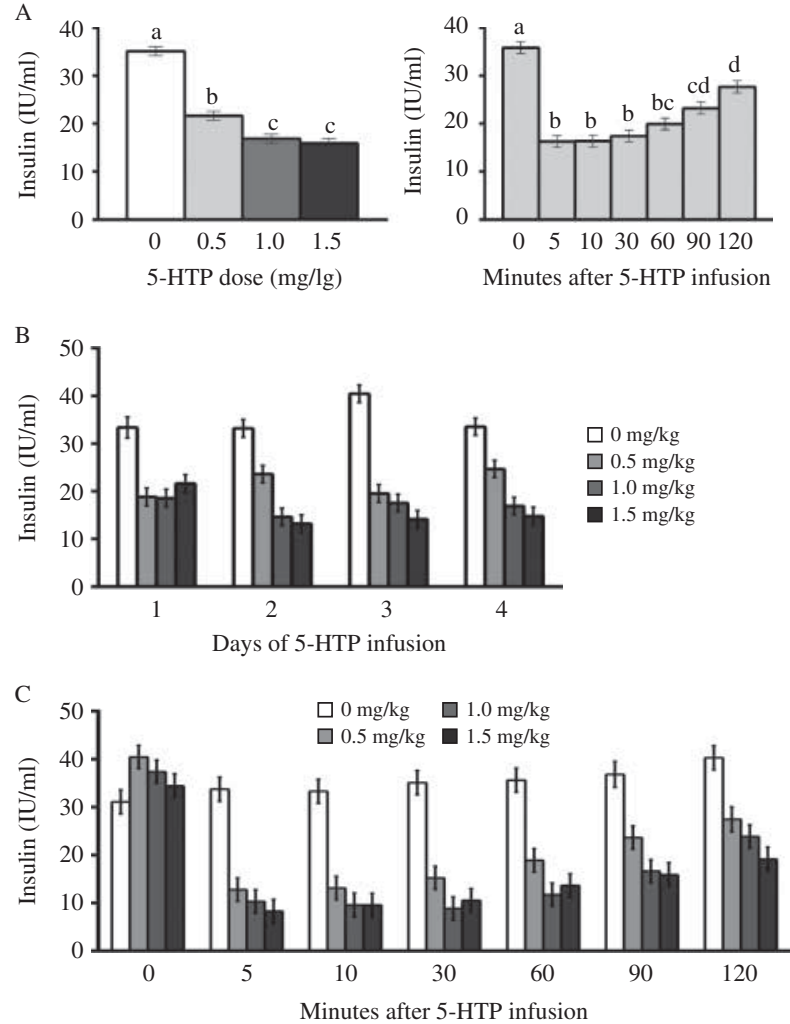

\section{Figure 4}

Circulating insulin concentrations in response to the i.v. infusion of four 5-hydroxy-L-tryptophan (5-HTP) doses $(0,0.5,1.0$, and $1.5 \mathrm{mg} / \mathrm{kg})$ for 4 consecutive days into late-lactation, non-pregnant Holstein dairy cows $(n=4)$. (A) Main effect of treatment (5-HTP dose) and (B) time after 5-HTP infusion (0-120 min). (C) Interaction between 5-HTP dose and day of infusion, and (D) interaction between 5-HTP dose and min after infusion. Different letters indicates statistical differences between group means (Tukey's $P<0.05$ ). Data are presented as LS means \pm s.E.M.

compared to the $\mathrm{CON}(P<0.001)$, and the 1.0 and 1.5 doses had higher NEFA concentrations as compared to the 0.5 dose $(P<0.003)$. This effect was primarily caused by the increase in NEFA concentrations over time after 5-HTP infusion. Circulating NEFA concentrations were elevated at $30 \mathrm{~min}$ as compared to $0 \mathrm{~min}$ and to $120 \mathrm{~min}(P<0.005)$. On days 3 and 4 of the 5-HTP infusion, NEFA concentrations were higher than they were on day $1(P<0.003)$, and this effect was primarily a result of the greater concentration of NEFA in the higher 5-HTP doses. No statistical differences between the baseline NEFA concentrations and the washout periods were observed $(P>0.05)$.

\section{Circulating $\beta$ HBA concentrations are decreased by 5-HTP infusion}

The AUC for $\beta \mathrm{HBA}$ was decreased in the $\mathrm{CON}$ as compared to the 1.0 dose $(P=0.02)$ and tended to be decreased on day 3 as compared to day 1 of the infusion ( $P=0.06$; data not shown). Concentrations of $\beta \mathrm{HBA}$ were affected by 5-HTP dose, time after infusion, and day of infusion $(P<0.0001$; Fig. 6A, B, and C). All of the 5-HTP doses decreased $\beta$ HBA concentrations as compared to the CON $(P<0.008)$, and the 1.0 and 1.5 doses decreased $\beta \mathrm{HBA}$ concentrations more robustly than the 0.5 dose did $(P<0.04$; Fig. 6A). Concentrations of $\beta \mathrm{HBA}$ decreased markedly the first $30 \mathrm{~min}$ after the 5-HTP infusion $(P<0.001)$ and then recovered to concentrations that were similar to the pre-infusion values $(0 \mathrm{~min})$ at 90 and 120 min after treatment (Fig. 6B). On days 2, 3 and 4 of 5 -HTP infusion, $\beta \mathrm{HBA}$ concentrations were higher than they were on day $1(P<0.03$; Fig. 6C). No statistical differences between baseline $\beta$ HBA concentrations and the washout periods were observed $(P>0.05)$.

\section{Circulating Ca concentrations are decreased by 5-HTP infusion}

The AUC for Ca was decreased by all of the 5-HTP doses as compared to the CON ( $P<0.0001$; data not shown). Circulating Ca concentrations were decreased by 5-HTP dose, time of infusion, and day of infusion, and there was a significant interaction between dose and time $(P<0.0001$; Fig. 7A, B, and C). All of the 5-HTP doses decreased Ca concentrations as compared to the CON $(P<0.0001$; Fig. 7A). The largest decrease in Ca concentration occurred on day 2 of infusion as compared to days 1,3 , and 4 $(P<0.0002$; Fig. 7B). Calcium concentrations decreased markedly at 30 min post-infusion (as compared to 0,5 , and $10 \mathrm{~min} ; P<0.0001$ ) for all of the 5-HTP doses, and they continued to decrease at 60 and $90 \mathrm{~min}$ postinfusion. Only the 0.5 dose subsequently increased and reached initial ( $0 \mathrm{~min}$ ) Ca concentrations at $120 \mathrm{~min}$ postinfusion (Fig. 7C). No statistical differences between the baseline Ca concentrations and the washout periods were observed $(P>0.05)$. Notably, cows on the present study had elevated $\mathrm{Ca}$ concentrations as a whole before the infusion of 5-HTP.

\section{Circulating PTHrP concentrations are decreased by 5-HTP infusion}

The AUC for PTHrP was lowest in the 1.5 dose as compared to the CON and 0.5 dose $(P<0.02$; data not shown). Circulating PTHrP concentrations were decreased by 5-HTP dose $(P<0.0001 ;$ Fig. $7 \mathrm{G})$ and time of infusion $(P=0.014$; Fig. $7 \mathrm{H})$. The two highest 5 -HTP doses decreased PTHrP concentrations as compared to both the

Published by Bioscientifica Ltd. 

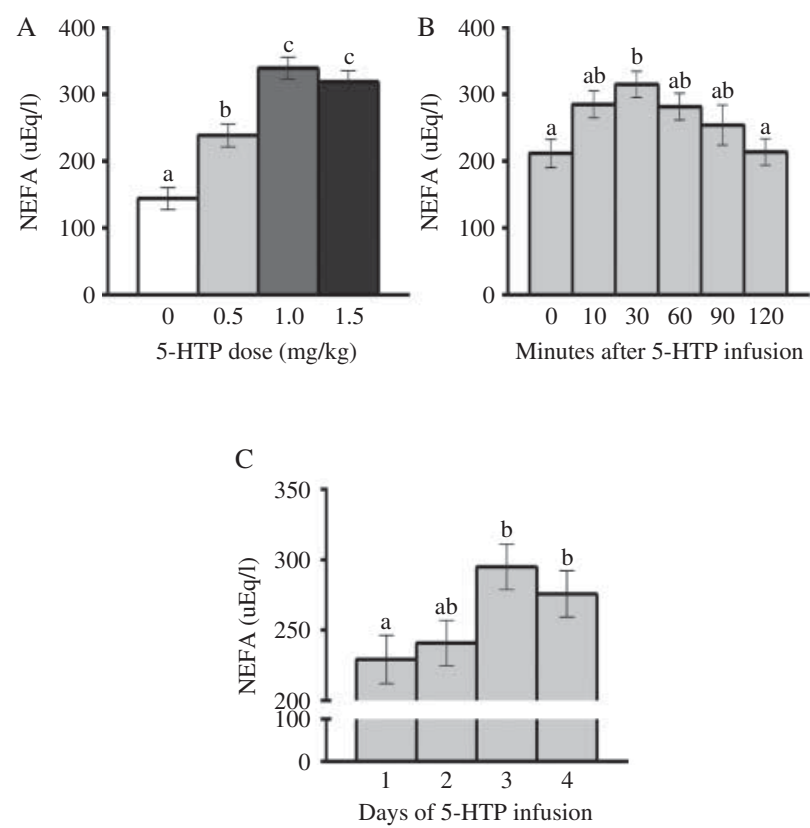

\section{Figure 5}

Circulating non-esterified fatty acid (NEFA) concentrations in response to the i.v. infusion of four 5-hydroxy-L-tryptophan (5-HTP) doses (0, 0.5, 1.0, and $1.5 \mathrm{mg} / \mathrm{kg}$ ) for 4 consecutive days into late-lactation, non-pregnant Holstein dairy cows $(n=4)$. (A) Main effect of treatment (5-HTP dose),

(B) time after 5-HTP infusion (0-120 $\mathrm{min}$ ), and (C) days of 5-HTP infusion

0.5 dose and the CON $(P<0.03$; Fig. 7G). Circulating concentrations of PTHrP decreased rapidly during the first 30 min of 5-HTP infusion as compared to the pre-infusion sample $(P<0.053)$ and then began to recover $(60,90$, and 120 min after infusion; Fig. 7H). No statistical differences between the baseline PTHrP concentrations and the washout periods were observed $(P>0.05)$.

\section{Infusion of 5-HTP alters Ca secretion in the urine and milk}

The percentage change between urine $\mathrm{Ca}(\mathrm{uCa})$ concentrations before (at $0 \mathrm{~min}$, pre-infusion) and after (at 120 min post-infusion) 5 -HTP or saline infusion was calculated as: ((uCa $120 \mathrm{~min}-\mathrm{uCa} \quad 0 \mathrm{~min}) /(\mathrm{uCa}$ 120 min) $) \times 100$. The percentage change in urine Ca loss was decreased by 5 -HTP dose $(P=0.04)$. Cows that received the highest doses of 5 -HTP $(1.0$ and $1.5 \mathrm{mg} / \mathrm{kg})$ had less uCa than the CON did $(P<0.04 ;$ Fig. 7D). Total Ca present in the milk was increased in the cows that received the 1.5 dose as compared to the CON ( $P=0.04$; Fig. 7E). Total milk phosphorous was increased in cows that received the 0.5 and 1.0 doses as compared to the $\mathrm{CON}$ $(P<0.06$; Fig. 7F).
D

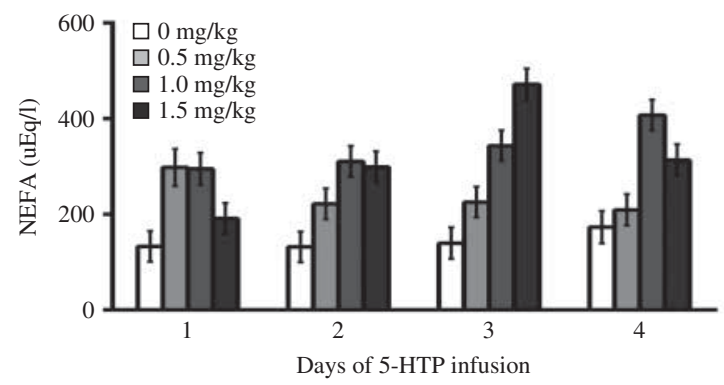

E $\quad 6007 \square 0 \mathrm{mg} / \mathrm{kg}$

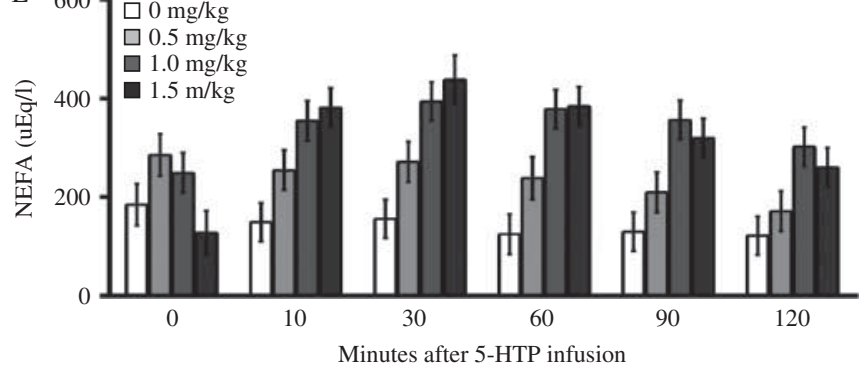

(1-4). (D) Interaction between day of infusion and 5-HTP dose, and (E) interaction between 5-HTP dose and min after infusion. Different letters indicates statistical differences between group means (Tukey's $P<0.05$ ). Data are presented as LS means \pm s.E.M.

\section{5-HTP treatment alters hepatic gene expression}

The hepatic expression of genes associated with glucose, fatty acid, and ketone synthesis were affected by the 5-HTP treatment. The mRNA expression of PDK4 tended to increase in cows that received the 1.5 dose as compared to the CON $(P=0.07)$, and $G 6 P$ tended to be increased by the 0.5 and 1.0 dose as compared to the CON $(P<0.10$; Fig. $8 \mathrm{~A}$ and $\mathrm{B})$. The mRNA expression of $H M G-C O A$ was increased in cows that received the highest 5-HTP doses (1.0 and $1.5 \mathrm{mg} / \mathrm{kg})$ as compared to the CON $(P<0.03$; Fig. 8C). The mRNA expression of both PPAR $\alpha$ and CPT1 tended to be increased in the 1.5 dose as compared to the CON and the baseline $(P<0.08$; Fig. $8 \mathrm{D}$ and $\mathrm{E})$. The $C P T 1$ mRNA expression was increased by 5 -HTP dose as compared to the CON and the baseline expression $(P<0.02$; Fig. $8 \mathrm{E})$. The expression of $A C A D V L$ tended to be increased by the 1.5 dose as compared to the baseline expression ( $P=0.07$; Fig. 8 F).

\section{Discussion}

Our previous data in Holstein dairy cows has implicated serotonin as an indicator of positive $\mathrm{Ca}$ and glucose status in lactating dairy cows (Laporta et al. 2013c). Those

Published by Bioscientifica Ltd 

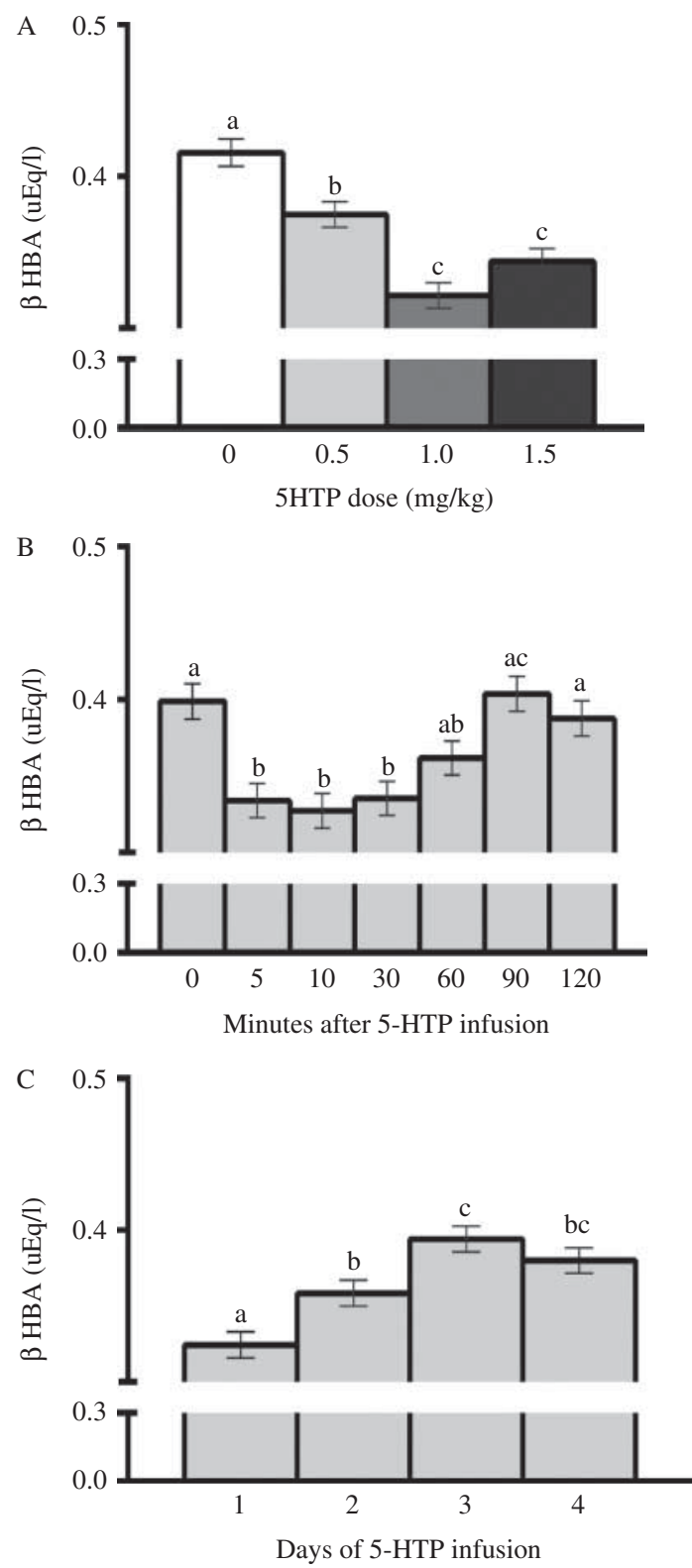

Figure 6

Circulating beta-hydroxybutyrate $(\beta \mathrm{HBA})$ concentrations in response to the i.v. infusion of four 5-hydroxy-L-tryptophan (5-HTP) doses (0, 0.5, 1.0, and $1.5 \mathrm{mg} / \mathrm{kg}$ ) for 4 consecutive days into late-lactation, non-pregnant Holstein dairy cows $(n=4)$. (A) Main effect of treatment (5-HTP dose), (B) time after 5-HTP infusion (0-120 min), and (C) days of 5-HTP infusion (1-4). Different letters indicates statistical differences between group means (Tukey's $P<0.05$ ). Data are presented as LS means \pm s.E.M.

observations prompted the hypothesis that increasing systemic serotonin in lactating cows may improve energy and $\mathrm{Ca}$ metabolism. Metabolites in the serotonergic pathway have been previously administered in several species to characterize various physiological responses. Particularly in bovines, serotonin was administered to calves to characterize their cardiovascular and pulmonary responses (Linden et al. 1993, 1996), and L-tryptophan was administered to steers to evaluate the effects on growth hormone secretion in cattle (Kasuya et al. 2010). However, to our knowledge, the present study is the first in which 5-HTP was administered to lactating dairy cows. We showed for the first time that increased systemic serotonin, through the administration of its immediate precursor 5-HTP, is safe, and it alters acute energy and Ca metabolism in lactating dairy cows.

Animal health was monitored by the evaluation of cow heart rate, RR, and RT in response to 5-HTP administration, and the findings demonstrated no significant impacts on animal health or behavior at any dose as compared to cows that received saline infusions. Additionally, we did not observe any changes in milk production as a result of any of the 5 -HTP doses. Because more than $90 \%$ of the available serotonin in the peripheral portion of the body is produced in the gastrointestinal tract and because serotonin is known to increase gastrointestinal transit (Gershon \& Tack 2007), we monitored defecation frequency and consistency in response to 5-HTP administration. As expected, manure frequency and score increased in a dose-dependent manner; however, we observed no outward signs of dehydration. It is important to note, though, that we did not evaluate hematocrit in these cows. Therefore, we conclude that administering 5-HTP to cows did not impact overall animal health and well-being.

In addition to determining the safety of 5-HTP administration, we examined the effects of various doses of 5-HTP treatment on Ca and energy metabolism as well as circulating serotonin concentrations. Importantly, infusing varying doses of 5-HTP for 4 days successfully increased systemic serotonin concentrations approximately twofold $(740 \pm 56 \mathrm{ng} / \mathrm{ml}$ vs $1560 \pm 140 \mathrm{ng} / \mathrm{ml}$ for the CON and average of serotonin doses respectively). Several lines of evidence suggest a role for serotonin in the regulation of energy balance, specifically in relation to glucose and fatty acid metabolism. Serotonin is known to induce hepatic regeneration (Lesurtel et al. 2006), glucose secretion from the liver, and insulin secretion by the pancreas (Sugimoto et al. 1990, Watanabe et al. 2011) as well as liver glucose uptake mechanisms (Moore et al. 2004, 2005) and glycogen metabolism (Papadimas et al. 2012). Furthermore, serotonin has been shown to regulate glucose-stimulated insulin secretion by the $\beta$ cells of the pancreas during pregnancy, and it is critical for glucosestimulated insulin secretion in an insulin-resistant state (Ohara-Imaizumi et al. 2013, Kim et al. 2015). Additionally, mice that were injected with increasing doses of

Published by Bioscientifica Ltd. 

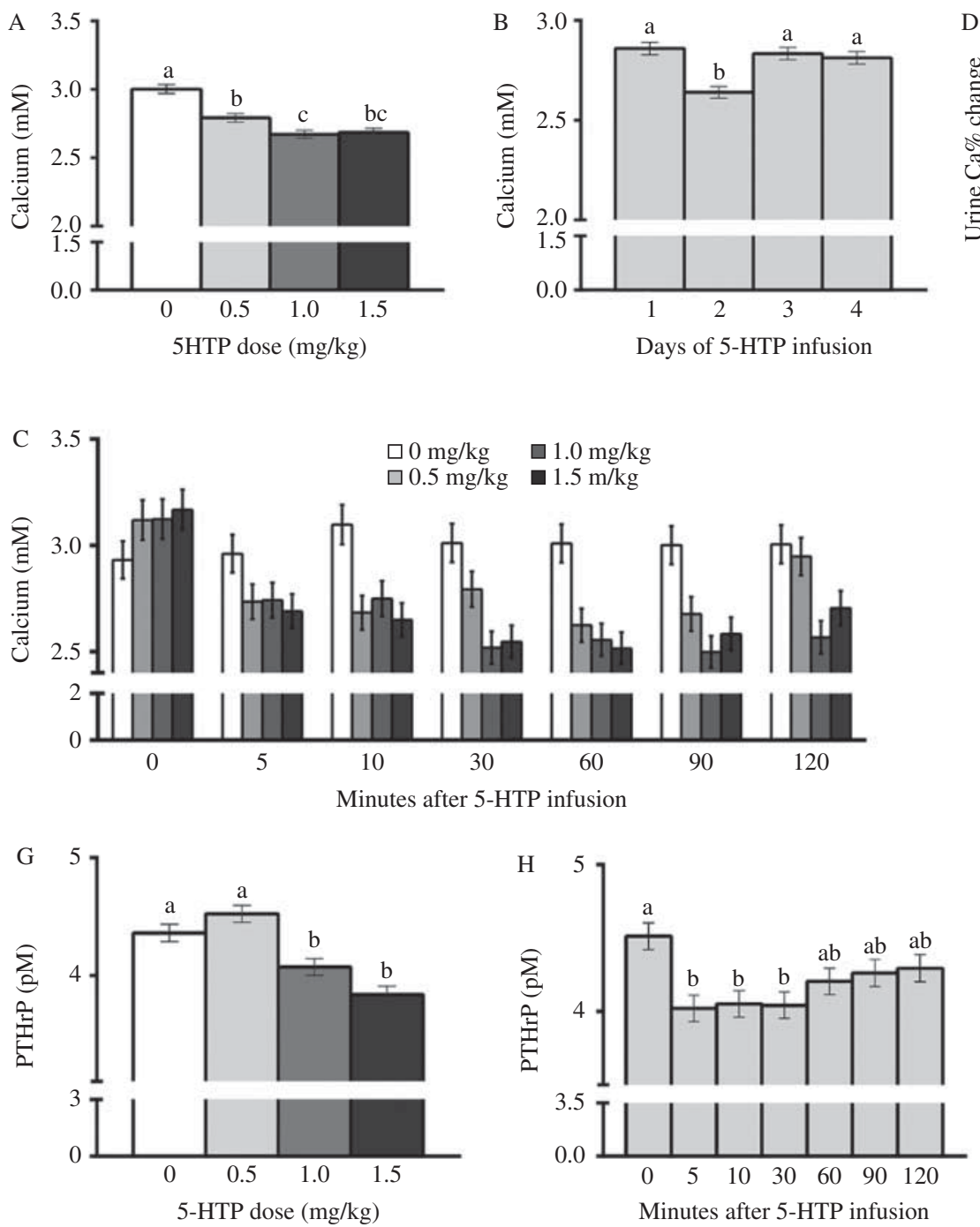
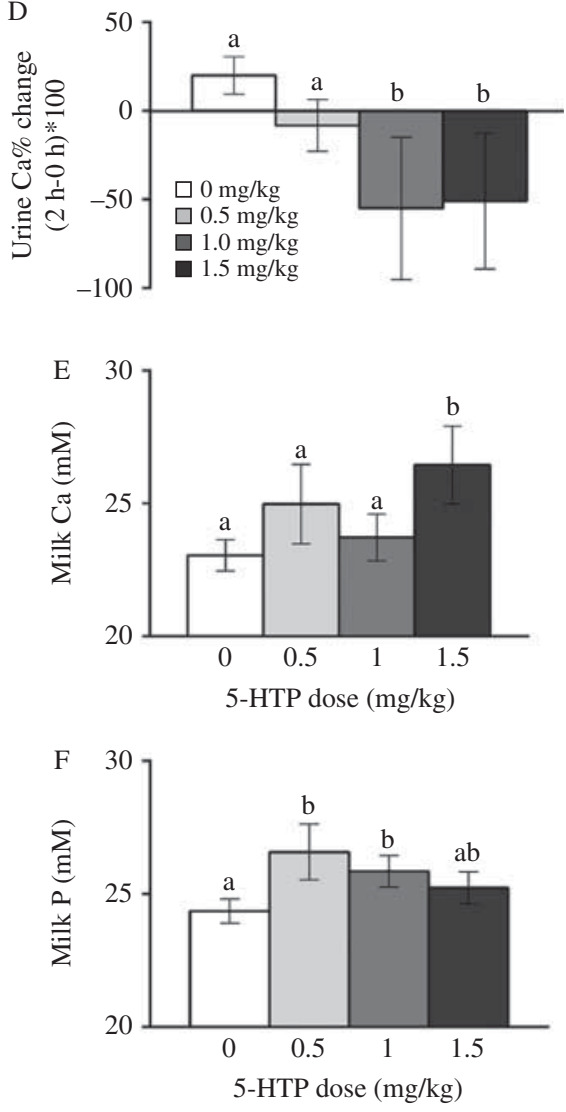

Figure 7

Serum calcium and plasma parathyroid hormone-related protein (PTHrP) concentrations in response to the i.v. infusion of four 5-hydroxy-Ltryptophan (5-HTP) doses $(0,0.5,1.0$, and $1.5 \mathrm{mg} / \mathrm{kg})$ for 4 consecutive days into late-lactation, non-pregnant Holstein dairy cows $(n=4)$. (A) Main effect of treatment (5-HTP dose), (B) days of 5-HTP infusion (1-4), and (C) interaction between 5 -HTP dose and min after infusion for calcium

serotonin were shown to have increased circulating leptin (Yamada et al. 1989) and free fatty acid concentrations (Sumara et al. 2012), which thus links serotonin with the regulation of fatty acid and energy metabolism.

At present, little is known about the involvement of serotonin in glucose and energy homeostasis during lactation. In the present study, elevated circulating serotonin concentrations resulted in increased circulating glucose concentrations and decreased $\beta \mathrm{HBA}$ concentrations, which indicates improved energy balance. Typically, concentrations. (D) Percentage change of urine calcium (uCa) calculated as: ((uCa $120 \mathrm{~min}-\mathrm{uCa} 0 \mathrm{~min}) /(\mathrm{uCa} 120 \mathrm{~min})) \times 100$ by 5 -HTP dose. (E and F) Milk calcium (Ca) and phosphorus (P) concentrations by 5-HTP dose. (G) Main effect of 5-HTP dose and $(\mathrm{H})$ time after infusion for PTHrP concentrations. Different letters indicates statistical differences between group means (Tukey's $P<.05$ ). Data are presented as LS means \pm s.E.M.

in instances of glucose deficiency, $\beta \mathrm{HBA}$ concentrations in the circulation are elevated (Bell \& Bauman 1997) and can result in ketosis, which negatively impacts cow health and immunity (Zarrin et al. 2014). This is of particular importance during the early lactation period, at which time dairy cows are in a negative energy balance (Duffield et al. 2009). It is likely that the rapid decrease in insulin concentrations in response to the 5-HTP treatment was responsible for the decrease in $\beta \mathrm{HBA}$ that was also observed in the present study. High insulin concentrations have

Published by Bioscientifica Ltd 


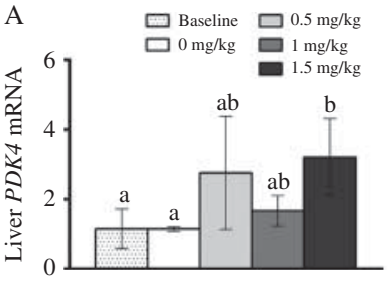

D
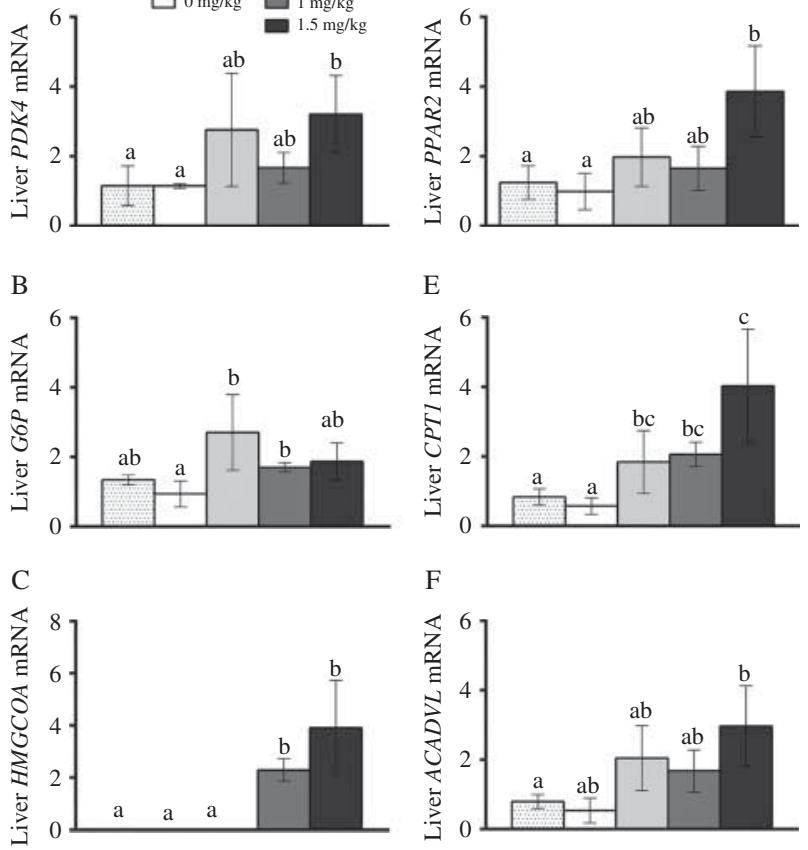

$\mathrm{F}$

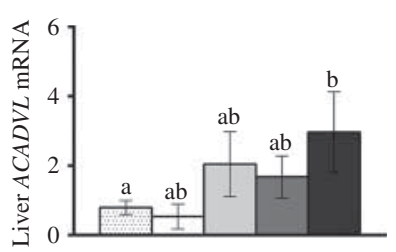

\section{Figure 8}

Hepatic mRNA expression of genes associated with glucose (pyruvate dehydrogenase kinase, isozyme 4, PDK4 (A); glucose-6-phosphatase, G6P (B)), ketone (3-hydroxy-3-methylglutaryl-CoA, HMG-COA (C)), and fatty acid (peroxisome proliferator-activated receptor $\alpha, P P A R \alpha(D)$; carnitine palmitoyltransferase 1, CPT1 (E); acyl-CoA dehydrogenase, very long chain, $A C A D V L(F))$ synthesis after the i.v. infusion of four doses $(0,0.5,1.0$, and $1.5 \mathrm{mg} / \mathrm{kg}$ ) of 5-hydroxy-L-tryptophan (5-HTP) for 4 consecutive days into late-lactation, non-pregnant Holstein dairy cows $(n=4)$. Liver tissue was harvested before the initiation of the experiment (baseline) and after 2 days of 5-HTP infusion. Different letters indicates statistical differences between group means (Tukey's $P<0.10$ ). Data are presented as LS means \pm s.E.M.

been previously reported to suppress ketogenesis (Hayirli et al. 2002, Li et al. 2013). Interestingly, in an experiment conducted in wethers that were fasted for $24 \mathrm{~h}$, i.v. treatment with serotonin, not 5-HTP, increased both glucose and insulin concentrations for $1 \mathrm{~h}$ post-treatment (Watanabe et al. 2014). This indicates that serotonin may act differently depending on the stage of the energy balance of the animal. Additionally, in the present study, we observed increased circulating NEFA concentrations; however, the NEFA concentrations were below the threshold that is considered to be unhealthy for a lactating dairy cow (Grummer 1993, LeBlanc 2010). The increase in NEFA could possibly improve milk fat synthesis without placing the lactating animal in a severe negative energy balance; however, this should be more thoroughly explored. I.v. administration of serotonin to wethers also increased NEFA concentrations $1 \mathrm{~h}$ post-treatment, but concentrations then returned to baseline (Watanabe et al.
2014). This suggests that even though we administered a serotonin precursor and not serotonin itself in the present study, the effects on NEFA concentrations would not have been long-lasting either way. The hepatic expression of key enzymes involved in gluconeogenesis (G6P and PDK4) and fatty acid metabolism (PPAR $\alpha, A C A D V L$, and CPT1) accompanied the observed increase in circulating glucose and NEFA circulations in response to 5-HTP. It is plausible that the increase in NEFAs in the circulation may be attributed to increased adipose tissue mobilization; however, in the present study, we did not directly test the effects of 5-HTP treatment on adipose tissue. The marked decrease observed in insulin and $\beta \mathrm{HBA}$ concentrations after 5-HTP administration might trigger the hepatic mRNA expression of $H M G-C O A$ as part of a negative feedback loop; however, this requires further exploration. Overall, 5-HTP treatment appears to alter energy metabolism in late-lactation dairy cows.

Infusion of all doses of 5-HTP acutely decreased circulating $\mathrm{Ca}$ and PTHrP concentrations, while also decreasing $\mathrm{Ca}$ excretion in urine and increasing $\mathrm{Ca}$ secretion into milk. This implies that 5-HTP treatment shifts Ca from maternal circulation to other tissues, for example, the mammary gland, seeing as it is not being excreted in the urine. Our previous work in mice demonstrated that serotonin is responsible for increasing Ca pumps in the mammary gland and secretion into milk (Laporta et al. 2013a, 2014a). The decrease in circulating Ca concentrations observed in the present study is in contrast to previous work in rodents where dietary 5-HTP supplementation increased circulating $\mathrm{Ca}$ and PTHrP concentrations (Laporta et al. 2013a). One plausible explanation for this is that in the present experiment, blood samples were collected during the $2 \mathrm{~h}$ post-infusion period, whereas in the previous rodent experiments, blood samples for measuring Ca and PTHrP in response to 5-HTP administration were collected after several days and up to 2 weeks after treatment (Laporta et al. 2013a, 2014b). This suggests that physiological responses to increased serotonin concentrations are different depending on the time point that is evaluated post-treatment. We have previously shown that PTHrP reached a maximal concentration in the circulation in response to 5-HTP in mice $3 \mathrm{~h}$ after treatment (Hernandez et al. 2012). Moreover, serotonin has been shown to cause physiological changes to tight junctions in the mammary epithelium in a biphasic manner in the mammary gland (Pai \& Horseman 2008). Therefore, the blood collection interval should be extended beyond the $2 \mathrm{~h}$ post-infusion period to establish if serotonin acts in a biphasic manner in the bovine.

Published by Bioscientifica Ltd 
Classically, $\mathrm{Ca}$ is regulated in a negative feedback manner, which means that decreased circulating Ca concentrations are necessary for inducing Ca mobilization from bone, and this process is necessary for supporting maternal $\mathrm{Ca}$ homeostasis during lactation (Kovacs 2005, Kovacs \& Fuleihan 2006). It is the decrease in circulating Ca concentrations that allows for PTHrP production in the mammary gland. This mechanism is supported by rodent experiments that have indicated that the trigger for PTHrP production in the mammary gland is the decrease in Ca concentrations that occur as a result of milk synthesis, as detected by the Ca sensing receptor located on the basolateral side of the mammary gland epithelium (Wysolmerski 2010, Kovacs 2011). It is also possible that the observed decrease in Ca may also contribute to changes in energy metabolism. Previous research has indicated that hypocalcemia can depress insulin concentrations in the circulation (Martinez et al. 2014). Therefore, we hypothesized that serotonin may increase Ca transport from the blood into the mammary gland and milk in order to initiate PTHrP production by the mammary gland. This hypothesis must be further studied in the bovine. Further research should focus on the examination of PTHrP and $\mathrm{Ca}$ concentrations at time points beyond the initial $2 \mathrm{~h}$ post-treatment as well as the specific effects of serotonin on Ca transport mechanisms within the mammary gland, and it should investigate whether 5-HTP treatment affects Ca homeostasis differentially during various stages of lactation. Finally, the interaction between serotonin's effect on $\mathrm{Ca}$ and glucose homeostasis during lactation should be further explored in cows.

In summary, the present data demonstrate that the administration of 5-HTP to lactating dairy cows was safe and increased systemic serotonin concentrations over time. Increased serotonin concentrations in turn impacted glucose, ketone, and fatty acid metabolism and increased $\mathrm{Ca}$ transport from the circulation into milk. We propose that serotonin is a key regulator of $\mathrm{Ca}$ and glucose metabolism and homeostasis in lactating dairy cows and suggest that the lactation stage specific physiological mechanisms should be further explored. It is possible that understanding serotonin's regulation of maternal metabolism during lactation will be important for the health and productivity of the dairy cow.

\section{Declaration of interest}

The authors declare that there is no conflict of interest that could be perceived as prejudicing the impartiality of the research reported.

\section{Funding}

The present study was supported by the USDA-HATCH Formula Fund, grant 142-PRJ74RD.

\section{Author contribution statement}

$\mathrm{J} L$ and $\mathrm{L} L \mathrm{H}$ designed, wrote, and analyzed the experiment. S A E M, SR W, C M C, B P S, A P P, and M O helped carry out the experiments. F P performed statistical analysis. F P, T D C, and R M B aided with the experimental design and analysis and contributed to the writing of the manuscript.

\section{References}

Amireault P, Sibon D \& Cote F 2013 Life without peripheral serotonin: insights from tryptophan hydroxylase 1 knockout mice reveal the existence of paracrine/autocrine serotonergic networks. ACS Chemical Neuroscience 4 64-71. (doi:10.1021/cn300154j)

Bell AW \& Bauman DE 1997 Adaptations of glucose metabolism during pregnancy and lactation. Journal of Mammary Gland Biology and Neoplasia 2 265-278. (doi:10.1023/A:1026336505343)

Berger M, Gray JA \& Roth BL 2009 The expanded biology of serotonin. Annual Review of Medicine 60 355-366. (doi:10.1146/annurev.med.60. 042307.110802)

Chabbi-Achengli Y, Coudert AE, Callebert J, Geoffroy G, Cote F, Collet C \& de Vernejoul M-C 2012 Decreased osteoclastogenesis in serotonindeficient mice. PNAS 109 2567-2572. (doi:10.1073/pnas.1117792109)

Cote F, Thevenot E, Fligny C, Fromes Y, Darmon M, Ripoche MA, Bayard E, Hanoun N, Saurini F, Lechat P et al. 2003 Disruption of the nonneuronal tph1 gene demonstrates the importance of peripheral serotonin in cardiac function. PNAS 100 13525-13530. (doi:10.1073/ pnas.2233056100)

Ducy P 2011 5-HT and bone biology. Current Opinion in Pharmacology 11 34-38. (doi:10.1016/j.coph.2011.01.007)

Duffield TF, Lissemore KD, McBride BW \& Leslie KE 2009 Impact of hyperketonemia in early lactation dairy cows on health and production. Journal of Dairy Science 92 571-580. (doi:10.3168/jds.2008-1507)

Gershon MD \& Tack J 2007 The serotonin signaling system: from basic understanding to drug development for functional GI disorders. Gastroenterology 132 397-414. (doi:10.1053/j.gastro.2006.11.002)

Grummer RR 1993 Etiology of lipid-related metabolic disorders in periparturient dairy-cows. Journal of Dairy Science 76 3882-3896. (doi:10.3168/jds.S0022-0302(93)77729-2)

Hayirli A, Bertics SJ \& Grummer RR 2002 Effects of slow-release insulin on production, liver triglyceride, and metabolic profiles of Holsteins in early lactation. Journal of Dairy Science 85 2180-2191. (doi:10.3168/jds. S0022-0302(02)74297-5)

Hernandez LL, Limesand SW, Collier JL, Horseman ND \& Collier RJ 2009 The bovine mammary gland expresses multiple functional isoforms of serotonin receptors. Journal of Endocrinology 203 123-131. (doi:10.1677/JOE-09-0187)

Hernandez LL, Gregerson KA \& Horseman ND 2012 Mammary gland serotonin regulates parathyroid hormone-related protein and other bone-related signals. American Journal of Physiology. Endocrinology and Metabolism 302 1009-1015. (doi:10.1152/ajpendo.00666.2011)

Horseman ND \& Hernandez LL 2014 New concepts of breast cell communication to bone. Trends in Endocrinology and Metabolism 25 34-41. (doi:10.1016/j.tem.2013.08.004)

Kasuya E, Yayou K-I, Hashizume T, Kitagawa S \& Sutoh M 2010 A possible role of central serotonin in L-tryptophan-induced GH secretion in cattle. Animal Science Journal 81 345-351. (doi:10.1111/j.1740-0929.2010.00747.x)

Kim K, Oh CM, Ohara-Imaizumi M, Park S, Namkung J, Yadav VK, Tamarina NA, Roe MW, Philipson LH, Karsenty G et al. 2015 Functional role of serotonin in insulin secretion in a diet-induced insulin-resistant state. Endocrinology 156 444-452. (doi:10.1210/en.2014-1687) 
Kovacs CS 2005 Calcium and bone metabolism during pregnancy and lactation. Journal of Mammary Gland Biology and Neoplasia 10 105-118. (doi:10.1007/s10911-005-5394-0)

Kovacs CS 2011 Calcium and bone metabolism disorders during pregnancy and lactation. Endocrinology and Metabolism Clinics of North America 40 795-826. (doi:10.1016/j.ecl.2011.08.002)

Kovacs CS \& Fuleihan Gel-H 2006 Calcium and bone disorders during pregnancy and lactation. Endocrinology and Metabolism Clinics of North America 35 21-51. (doi:10.1016/j.ecl.2005.09.004)

Laporta J, Peters TL, Weaver SR, Merriman KE \& Hernandez LL 2013 $a$ Feeding 5-hydroxy-L-tryptophan during the transition from pregnancy to lactation increases calcium mobilization from bone in rats. Domestic Animal Endocrinology 44 176-184. (doi:10.1016/j.domaniend.2013.01.005)

Laporta J, Peters TL, Merriman KE, Vezina CM \& Hernandez LL $2013 b$ Serotonin (5-HT) affects expression of liver metabolic enzymes and mammary gland glucose transporters during the transition from pregnancy to lactation. PLOS ONE 8 57847. (doi:10.1371/journal.pone. 0057847)

Laporta J, Moore SAE, Peters MW, Peters TL \& Hernandez LL $2013 c$ Circulating serotonin (5-HT) concentrations on day 1 of lactation as a potential predictor of transition-related disorders. Journal of Dairy Science 96 5146-5150. (doi:10.3168/jds.2013-6718)

Laporta J, Keil KP, Vezina CM \& Hernandez LL 2014a Peripheral serotonin regulates maternal calcium trafficking in mammary epithelial cells during lactation in mice. PLoS ONE 9 110190-110190. (doi:10.1371/ journal.pone.0110190)

Laporta J, Keil KP, Weaver SR, Cronick CM, Prichard AP, Crenshaw TD, Heyne GW, Vezina CM, Lipinski RJ \& Hernandez LL 2014b Serotonin regulates calcium homeostasis in lactation by epigenetic activation of hedgehog signaling. Molecular Endocrinology 28 1866-1874. (doi:10.1210/me.2014-1204)

Leblanc S 2010 Monitoring metabolic health of dairy cattle in the transition period. Journal of Reproduction and Development 56 29-35. (doi:10.1262/jrd.1056S29)

Lesurtel M, Graf R, Aleil B, Walther DJ, Tian YH, Jochum W, Gachet C, Bader M \& Clavien PA 2006 Platelet-derived serotonin mediates liver regeneration. Science 312 104-107. (doi:10.1126/science.1123842)

Li P, Wu CC, Long M, Zhang Y, Li XB, He JB, Wang Z \& Liu GW 2013 Short communication: high insulin concentrations inhibit fatty acid oxidation-related gene expression in calf hepatocytes cultured in vitro. Journal of Dairy Science 96 3840-3844. (doi:10.3168/jds.2012-6160)

Linden AS, Desmecht DJ, Amory H, Rollin FA \& Lekeux PM 1993 Comparison of 3 metrenperone dosage regimens inhibiting the 5-hydroxytryptamine-induced pulmonary dysfunction in cattle. Research in Veterinary Science 55 25-30. (doi:10.1016/0034-5288(93)90029-F)

Linden AS, Desmecht DJ, Amory H \& Lekeux PM 1996 Parasympathetic component of 5-hydroxytryptamine-induced pulmonary dysfunctions in healthy calves. American Journal of Veterinary Research 57 896-901.

Livak KJ \& Schmittgen TD 2001 Analysis of relative gene expression data using real-time quantitative PCR and the $2\left({ }^{-\Delta \Delta} \mathrm{Ct}\right)$ method. Methods $\mathbf{2 5}$ 402-408. (doi:10.1006/meth.2001.1262)

Lucki I 1998 The spectrum of behaviors influenced by serotonin. Biological Psychiatry 44 151-162. (doi:10.1016/S0006-3223(98)00139-5)

Martinez N, Sinedino LD, Bisinotto RS, Ribeiro ES, Gomes GC, Lima FS, Greco LF, Risco CA, Galvão KN, Taylor-Rodriguez D et al. 2014 Effect of induced subclinical hypocalcemia on physiological responses and neutrophil function in dairy cows. Journal of Dairy Science 97 874-887. (doi:10.3168/jds.2013-7408)

Matsuda M, Imaoka T, Vomachka AJ, Gudelsky GA, Hou ZY, Mistry M, Bailey JP, Nieport KM, Walther DJ, Bader M et al. 2004 Serotonin regulates mammary gland development via an autocrine-paracrine loop. Developmental Cell 6 193-203. (doi:10.1016/S15345807(04)00022-X)
Moore MC, Geho WB, Lautz M, Farmer B, Neal DW \& Cherrington AD 2004 Portal serotonin infusion and glucose disposal in conscious dogs. Diabetes 53 14-20. (doi:10.2337/diabetes.53.1.14)

Moore MC, Kimura K, Shibata H, Honjoh T, Saito M, Everett CA, Smith MS \& Cherrington AD 2005 Portal 5-hydroxytryptophan infusion enhances glucose disposal in conscious dogs. American Journal of Physiology. Endocrinology and Metabolism 289 225-231. (doi:10.1152/ ajpendo.00614.2004)

Ohara-Imaizumi M, Kim H, Yoshida M, Fujiwara T, Aoyagi K, Toyofuku Y, Nakamichi Y, Nishiwaki C, Okamura T, Uchida T et al. 2013 Serotonin regulates glucose-stimulated insulin secretion from pancreatic $\beta$ cells during pregnancy. PNAS 110 19420-19425. (doi:10.1073/pnas. 1310953110)

Pai VP \& Horseman ND 2008 Biphasic regulation of mammary epithelial resistance by serotonin through activation of multiple pathways. Journal of Biological Chemistry 283 30901-30910. (doi:10.1074/jbc. M802476200)

Papadimas GK, Tzirogiannis KN, Mykoniatis MG, Grypioti AD, Manta GA \& Panoutsopoulos GI 2012 The emerging role of serotonin in liver regeneration. Swiss Medical Weekly 142 13548. (doi:10.4414/smw.2012. 13548)

R Development Core Team 2015 In $R$ : a language and environment for statistical computing. Vienna, Austria: R Foundation for Statistical Computing.

Rortvedt LA \& Crenshaw TD 2012 Expression of kyphosis in young pigs is induced by a reduction of supplemental vitamin $\mathrm{D}$ in maternal diets and vitamin D, Ca, and P concentrations in nursery diets. Journal of Animal Science 90 4905-4915. (doi:10.2527/jas.2012-5173)

Rozen S \& Skaletsky H 2000 Primer3 on the www for general users and for biologist programmers. Methods in Molecular Biology 132 365-386 (www.ncbi.nlm.nih.gov/pubmed/10547847).

Sugimoto Y, Kimura I, Yamada J, Watanabe Y, Takeuchi N \& Horisaka K 1990 Effects of serotonin on blood-glucose and insulin levels of glucose-treated and streptozotocin-treated mice. Japanese Journal of Pharmacology 54 93-96. (doi:10.1254/jjp.54.93)

Sumara G, Sumara O, Kim JK \& Karsenty G 2012 Gut-derived serotonin is a multifunctional determinant to fasting adaptation. Cell Metabolism 16 588-600. (doi:10.1016/j.cmet.2012.09.014)

Tecott LH 2007 Serotonin and the orchestration of energy balance. Cell Metabolism 6 352-361. (doi:10.1016/j.cmet.2007.09.012)

Vicari T, van den Borne JJ, Gerrits WJ, Zbinden Y \& Blum JW 2008 Postprandial blood hormone and metabolite concentrations influenced by feeding frequency and feeding level in veal calves. Domestic Animal Endocrinology 34 74-88. (doi:10.1016/j.domaniend.2006.11.002)

Watanabe H, Rose MT \& Aso H 2011 Role of peripheral serotonin in glucose and lipid metabolism. Current Opinion in Lipidology 22 186-191. (doi:10.1097/MOL.0b013e3283462273)

Watanabe H, Saito R, Nakano T, Takahashi H, Takahashi Y, Sumiyoshi K, Sato K, Chen X, Okada N, Iwasaki S et al. 2014 Effect of peripheral 5-HT on glucose and lipid metabolism in wether sheep. PLoS ONE 9 e88058. (doi:10.1371/journal.pone.0088058)

Wysolmerski JJ 2010 Interactions between breast, bone, and brain regulate mineral and skeletal metabolism during lactation. Annals of the New York Academy of Sciences 1192 161-169. (doi:10.1111/j.1749-6632. 2009.05249.x)

Yamada J, Sugimoto Y, Kimura I, Takeuchi N \& Horisaka K 1989 Serotonin-induced hypoglycemia and increased serum-insulin levels in mice. Life Sciences 45 1931-1936. (doi:10.1016/0024-3205(89) 90547-X)

Zarrin M, Wellnitz O, van Dorland HA \& Bruckmaier RM 2014 Induced hyperketonemia affects the mammary immune response during lipopolysaccharide challenge in dairy cows. Journal of Dairy Science $\mathbf{9 7}$ 330-339. (doi:10.3168/jds.2013-7222)

Received in final form 9 May 2015

Accepted 13 May 2015

Published by Bioscientifica Ltd. http://joe.endocrinology-journals.org

DOI: $10.1530 / \mathrm{JOE}-14-0693$
(C) 2015 Society for Endocrinology Printed in Great Britain 